\title{
A Matemática na Vida do Cidadão
}

R.J.C. VALLADARES ${ }^{1}$, Instituto de Educação Matemática, USU, Rua Fernando Ferrari 75, 22231-040 Rio de Janeiro, RJ, Brasil.

Resumo. Um dos objetivos deste artigo é examinar algumas situações correntes na vida do cidadão, para perceber a presença, a ausência, o bom ou mau uso de recursos matemáticos. Além disso, procuraremos identificar os aspectos técnicos ou culturais da Matemática, nas situações examinadas. Outro objetivo é sugerir maneiras de usar este estudo nos processos de ensino/aprendizagem de Matemática nos diversos níveis de ensino. Afinal, cabe a nós - que ensinamos esta ciência - informar a sociedade e, em especial, nossos alunos e suas famílias, acerca das possibilidades de usar a Matemática na vida das pessoas. Uma boa maneira de iniciar este trabalho de informação, é levar esta discussão para a sala de aula. Isto torna possível que se chegue ao ensino de alguns tópicos matemáticos, a partir da observação destes tópicos, na vida corrente. Neste trabalho, serão descritos alguns procedimentos que foram sugeridos em um curso de aperfeiçoamento de professores de Matemática, ministrado pelo autor. Alguns professores usaram estas sugestões e obtiveram bons resultados.

\section{Matemática na Imprensa}

Para perceber o quanto o bom uso da Matemática é importante para o cidadão se informar através da imprensa, vejamos as seguintes notícias que foram publicadas na TV e em jornais de grande circulação na região metropolitana do Rio de Janeiro.

i) “... o sedã se viu obrigado a recorrer à sua potência para superar inclinações de 70 graus...".

Neste texto, faltou sensibilidade matemática ao jornalista que o escreveu, pois ele cometeu um erro geométrico óbvio na notícia, já que um automóvel não pode superar uma inclinação de 70 graus.

ii) “... numa ribanceira de cerca de 30 graus de inclinação e três metros de largura ..."

Este texto é parte de uma reportagem que descreve a margem de um rio. No caso, o jornalista usou de forma correta as noções geométricas envolvidas.

iii) Em um noticiário de TV, a apresentadora disse que “... agora, maiores de 14 anos não podem mais dirigir ciclomotores...".

\footnotetext{
${ }^{1}$ rjcv@mailbr.com.br
} 
A reportagem se referia às normas legais para dirigir ciclomotores, que foram modificadas, aumentando para 18 anos, a idade mínima para conduzir estes veículos.

Como uma proibição para maiores de 14 anos inclui as pessoas que tenham 14, 16, 18, 27 ou 53 anos, a reportagem continha um erro. Este erro decorreu do uso incorreto da relação de ordem dos números reais.

iv) Ainda sobre o mesmo assunto, um jornal publicou notícia dizendo que "Adolescentes com idades entre 16 e 18 anos estão proibidos de guiar mobiletes e outras pequenas motocicletas."

Adolescentes com 13 anos, embora fora da faixa entre 16 e 18, também estão proibidos de dirigir estas motos. Entretanto, a notícia não informa este fato, o que reduz seu potencial de informação. Isto ocorreu devido à fixação da faixa acima, o que recai na relação de ordem. Assim, o mau uso desta causou o problema.

v) Em crônica sobre a tabela de contagem de pontos do campeonato brasileiro de futebol, era estabelecido o percentual de chances de classificação de oito clubes que disputavam três vagas. Desta forma, o cronista usava a porcentagem para informar os leitores sobre as chances de cada clube.

Textos como estes podem ser discutidos pelos estudantes. O professor pode pedir que estes identifiquem os aspectos matemáticos usados, bem como a adequação ou a inadequação do uso feito, enfatizando a forma como estes aspectos facilitam ou dificultam a compreensão do texto. Assim, quando o jornal informou que o carro subiu uma ladeira de 70 graus, obscureceu o texto. Já o texto (ii) ficou mais claro quando descreveu a margem do rio, citando sua inclinação e sua largura. Quando o professor estiver ministrando tópicos de geometria, pode apresentar textos como estes aos alunos e discutir os recursos matemáticos empregados na redação de cada um deles. Os textos (iii) e (iv) ficaram obscuros devido ao uso inadequado da relação de ordem, enquanto texto (v) tornou-se mais claro quando apresentou os percentuais de chances de cada clube se classificar.

\section{Comparações Esclarecedoras}

vi) Em uma notícia sobre uma fazenda o leitor era informado sobre certos fatos que ocorreram “... na fazenda Barriguda, de 4.900 hectares ...”.

Se compararmos o texto acima com o texto (ii), vemos que sob o ponto vista geométrico, ambos estão bem formulados. Ambos usam unidades correntes de comprimento, área e ângulo. Entretanto, se considerarmos que ambas as notícias foram publicadas em jornais com circulação em uma região urbana, vemos que a notícia (ii) informa bem o leitor, pois é fácil imaginar a margem descrita. Já sobre a notícia (vi) não se pode dizer a mesma coisa. É praticamente impossível, para o habitante médio de uma região urbana, imaginar o tamanho de uma fazenda com 4.900 hectares. Afinal, trata-se de um cidadão urbano que, quando muito, aprendeu na escola que um hectare tem $10.000 \mathrm{~m}^{2}$. Esta informação ajuda muito pouco na 
avaliação do tamanho de uma fazenda com 4.900 hectares. Se ele estiver disposto fazer as contas saberá que a fazenda tem 49 milhões de metros quadrados. Entretanto, para uma pessoa que tem a experiência de vida de quem freqüenta salas com 15,20 ou $30 \mathrm{~m}^{2}$ ou sabe o que são lotes de terra com 200, 350 ou $500 \mathrm{~m}^{2}$, é praticamente impossível entender o sejam 49 milhões de metros quadrados. Coloca-se então, o problema de encontrar uma maneira de tornar a notícia mais clara.

vii) A própria imprensa dá a solução quando descreve o parque de uma cidade vizinha ao Rio de Janeiro, dizendo que "O parque municipal de Nova Iguaçú mede 1,1 mil hectares, o que equivale a 10 aterros do Flamengo ou ao tamanho do bairro de Copacabana.".

Tal como (vi), este texto também descreve uma grande área de terra. Diferente de (vi) o autor desta reportagem teve sensibilidade matemática para perceber que seria difícil para o leitor, aquilatar uma área 1,1 mil hectares. Para resolver este problema, fez comparações com um parque e um bairro situados no Rio de Janeiro, ambos muito bem conhecidos pelo leitor médio do jornal. Desta maneira, foram dados elementos para que o leitor pudesse aquilatar o tamanho do parque que era descrito. Assim, a notícia ficou mais clara e o leitor ficou melhor informado.

Vale observar que as comparações têm um caráter complementar, não devendo substituir a informação quantitativa em termos de uma unidade de medida corrente. Para ver isto, observemos o texto a seguir.

viii) Uma notícia sobre exploração de petróleo no mar informava que certa plataforma "Mede mais de três campos do Maracanã e pesa sete vezes mais que o Titanic.".

Neste caso, a ordem de grandeza do tamanho e do peso da plataforma são comparados com o campo de futebol do Maracanã e o peso do Titanic. Entretanto, a notícia falha por não informar estas dimensões em unidades correntes de medida.

\section{Aspectos Culturais}

Como comparações quantitativas são feitas com auxílio da relação de ordem, concluímos que esta relação foi convenientemente usada na notícia (vii) e deixou de ser usada na notícia (vi). Entretanto, comparando (vi) e (vii) com (iii) e (iv), onde a relação de ordem também apareceu, vemos que há uma grande diferença entre as maneiras de usar esta relação, nestes textos. Para identificar esta diferença, imaginemos a existência de dois jornais, "O Diário de Nova Iguaçú", com circulação na cidade de Nova Iguaçú e a "A Gazeta Rural", especializada em assuntos rurais. Se a "Gazeta" publicasse uma reportagem sobre a fazenda Barriguda, poderia formula-la como em (vi), escrevendo “... na fazenda Barriguda, de 4.900 hectares ...”. Neste caso, a reportagem seria bem compreendida, pois um leitor habituado a tratar com assuntos rurais é suficientemente esclarecido sobre tamanhos de fazendas, dispensando qualquer comparação. 
Da mesma maneira, se o "Diário" fizesse uma reportagem sobre o parque de Nova Iguaçú, seria inconveniente usar a formulação (vii), pois para o leitor deste jornal (provável conhecedor de Nova Iguaçú), uma comparação com um parque ou um bairro de outra cidade, é inadequada. Vemos assim, que para a "Gazeta" e o "Diário", as críticas feitas aos textos (vi) e (vii), se inverteriam.

Entretanto, os texto (iii) e (iv) sobre as alterações na lei para dirigir ciclomotores, que estavam mal formulados onde foram publicados, continuariam mal formulados se fossem publicados na "Gazeta", no "Diário" ou em qualquer outro jornal. O mesmo acontece com o texto (viii), que em qualquer meio de comunicação deveria dar o peso e o tamanho da plataforma, em unidades correntes de medida.

Vemos assim, que a correção ou a incorreção do uso da relação de ordem nos textos (iii) e (iv) tem um caráter mais geral, que depende menos dos contextos onde aparecem as notícias. Nos textos (vi) e (vii), este uso tem um caráter mais relativo. Depende de onde sejam publicados os textos. Isto ocorre porque a relação de ordem nos textos (iii) e (iv), tem um aspecto técnico bem determinado no qual seu uso pode ser classificado de maneira precisa, como sendo "correto ou incorreto". O mesmo ocorre com as noções geométricas nos textos (i) e (ii), com os percentuais probabilísticos no texto $(\mathrm{v})$ ou com as unidades de medidas que não aparecem no texto (viii).

Entretanto, nos textos (vi) e (vii) a relação de ordem não desempenha papeis técnicos. Retornando aos textos, podemos ver que a correção deles independe das comparações. Isto é, tanto o texto (vi) como o texto (vii) estão corretos, embora num deles não exista nenhuma comparação, enquanto no outro existem duas. Assim, com respeito a estes textos, os usos da relação de ordem podem ser melhor classificados como "conveniente" ou "inconveniente". Identificamos assim, aspectos culturais neste uso. Tanto quanto os aspectos técnicos, os aspectos culturais também podem ser usados nas aulas de Matemática, dotando o professor de recursos que no presente despertam o interesse dos alunos, facilitando os processos de ensino/aprendizagem. No futuro estes aspectos se integrarão na formação cultural do cidadão que o aluno será, o que muito o ajudará ao longo da vida. Este tipo de trabalho os habilitará a lidar melhor com informações quantitativas, o que certamente será importante em suas vidas, quer seja para compreenderem as informações que vierem a receber, quer seja para formularem informações, caso venham a optar por uma profissão ligada às comunicações sociais, como por exemplo, o jornalismo. Neste sentido, a notícia (vi) sobre a fazenda Barriguda pode ser discutida em sala. Os estudantes podem melhora-la, estabelecendo comparações com praças, parques ou mesmo toda a cidade onde eles moram.

Ao abordar o sistema métrico decimal, o professor pode propor o problema de expressar a área da fazenda em quilômetros quadrados. Ainda na abordagem do sistema métrico, o professor pode observar que no texto (vii), ao informar a medida do parque usando a expressão “...1,1 mil..." em vez de 1.100, o repórter pensou no número 1.000 como um múltiplo decimal do número 1. Assim, aplicou aos números, as noções de múltiplo e sub-múltiplo, usada no sistema métrico decimal. Como estas noções têm sua origem no sistema decimal de numeração, percebe-se que na Matemática cultural usada na reportagem, as noções que se originaram 
no sistema de numeração para descrever o sistema métrico, retornaram às origens quando foram usadas pelo jornalista.

\section{O Jeito Matemático de Pensar ${ }^{1}$}

Dando seqüência aos aspectos culturais, o professor pode aproveitar certas situações para usar o jeito matemático de pensar fora de situações matemáticas. Por exemplo, o uso de hipóteses de trabalho, tão comum em Matemática, pode ser estendido a problemas de outra natureza. O professor pode formular problemas com os jornais hipotéticos "A Gazeta Rural" e "O Diário de Nova Iguaçú" citados um pouco atrás. Neste caso, ao discutir com a turma a respeito da fazenda Barriguda e do parque de Nova Iguaçú, pode ser proposto um problema que peça para eles escreverem uma "reportagem" a ser publicada no "Diário", citando a área da fazenda. Da mesma forma, a questão da plataforma de petróleo (texto (viii)), pode dar origem a uma "notícia" na "Gazeta", onde a tonelagem de navios seja comparada à capacidade de um armazém rural.

Simultaneamente, podem ser abordadas situações matemáticas. Será interessante comparar a formulação do teorema de Pitágoras escrito sob a forma "Se ABC for um triângulo retângulo, então ....", com a conclusão sobre a reportagem no "Diário" escrita sob a forma "Se o Diário for um jornal com circulação em Nova Iguaçu, então a reportagem deve comparar a área da fazenda Barriguda com a do parque desta cidade.". Da mesma forma, um enunciado como "Sabendo-se que $a_{1}, a_{2}, \cdots, a_{n}$ é uma progressão geométrica, com razão 2 e $a_{1}=3$, então a soma dos 8 primeiros termos será....", pode ser comparado com uma formulação do tipo "Sabendo-se que o Titanic deslocava 45.000 toneladas e que um certo armazém pode estocar 500 toneladas de grãos, então a Gazeta deve noticiar que a tonelagem do navio era 90 vezes maior que a capacidade do armazém".

Enunciados do tipo "Os elementos de comparação devem ser bem conhecidos pelo leitor" podem ser comparados com enunciados matemáticos tais como "O quadrado da soma de dois números reais $a$ e $b$ é dada pela expressão ...". O professor pode deixar claro que enquanto o enunciado sobre as comparações foi usado para resolver o problema da reportagem do "Diário", o enunciado matemático pode ser usado para calcular um valor numérico, para fazer uma fatoração ou para completar um quadrado e determinar o centro de uma circunferência.

Este tipo de procedimento liberta o jeito matemático de pensar, do uso restrito em situações matemáticas, tornado-o disponível para abordar outras situações. Amplia-se desta maneira, a formação matemática do cidadão, fazendo com que esta ciência interfira cada vez mais em sua vida, aguçando a sensibilidade matemática e dotando-o de uma maneira de raciocinar segura e confiável.

As reportagens sobre a idade para dirigir ciclomotores ((iii) e (iv)) apresentam uma discordância entre elas, uma dizia que "... agora, maiores de 14 anos não podem mais dirigir ciclomotores..." enquanto a outra noticiou que "Adolescentes com idades entre 16 e 18 anos estão proibidos de guiar mobiletes e outras pequenas

${ }^{1}$ Marca em processo de registro 
motocicletas.". O professor pode usar esta discordância para propor um exercício sobre o jeito matemático de pensar, cujo objetivo seja discutir o erro. Para isto, pode usar a abordagem por casos, que é um procedimento muito usado em situações matemáticas.

Assim (caso 1) pode-se iniciar supondo que a idade revogada era de 14 anos e concluir que o texto (iii) está correto e o texto (iv) está errado. Seguindo esta linha de raciocínio os alunos formularão os demais casos. Muito provavelmente, um deles constatará que um dos casos deve admitir a hipótese de ambas as reportagens estarem erradas.

\section{Mais Matemática na Imprensa}

ix) “... o consultor George Freund disse que sua equipe gastou 40.000 horas preparando a avaliação da Telebrás. Levando-se em conta que eles trabalharam durante três meses, ficam faltando horas para completar a labuta. Em 90 dias, o máximo que se pode trabalhar são 2.160 horas ...".

O tom de perplexidade da reportagem mostra que o repórter não percebeu que as 40.000 horas citadas pelo consultor, foram estimadas multiplicando-se o número de funcionários pelo número de horas trabalhadas. Ao não perceber isto, o jornalista acreditou que havia um erro na fala do consultor. Para evidencia-lo, multiplicou as 24 horas de um dia pelos 90 dias trabalhados e chegou ao número de $(24 \times 90=) 2.160$ horas. Assim, ao não ter sensibilidade matemática para perceber a forma como as 40.000 horas foram estimadas, o jornalista se valeu de uma multiplicação para mostrar um erro que não existia. É interessante notar que a conta $(24 \times 90=2.160)$ está correta. Seu uso, entretanto, foi inadequado.

x) Em uma reportagem sobre botequins, lia-se que os azulejos eram "assentados em losango".

Nesta notícia o repórter abrandou o rigor matemático na caracterização dos losangos e se valeu da maneira como muitos autores de Matemática ilustram seus livros com figuras destes polígonos. Quem tiver estudado em um destes livros, não terá a menor dúvida em concluir que a reportagem dizia que os azulejos são assentados com uma diagonal na vertical. Assim, o repórter usou um conceito matemático de uma maneira livre para executar bem, o trabalho de informar.

Comparando as notícias acima, vemos que a primeira efetuou corretamente uma multiplicação. Apesar disto, chegou a uma conclusão incorreta. A segunda, alterou o sentido matemático da noção de losango, para conseguir um efeito correto. Este tipo de discussão pode ser feito em sala de aula, com resultados positivos para a formação cultural dos estudantes.

\section{Matemática na Propaganda}

xi) A propaganda de um carro enfatizava as belezas do modelo anunciado, dizendo que ele tinha as lanternas traseiras cortadas em diagonal. Chamando atenção 
para a diferença entre este e os outros modelos, a referência geométrica enfatizava que a diferença valorizava o carro. Tal como na notícia sobre os botequins, o publicitário teve sensibilidade matemática ao abrandar a rigidez geométrica que caracteriza a noção de diagonal e, assim, fazer melhor o seu trabalho.

xii) A propaganda de uma rede de TV a cabo, após falar nas muitas qualidades que oferecia, referia-se ao preço que para parecer menor, tinha o valor da mensalidade dividido por 30 . O pequeno quociente assim obtido era anunciado por uma voz que dizia "... pague somente algumas moedas por dia".

Este recurso matemático fez o custo parecer menor, estimulando as pessoas a usarem os serviços oferecidos. Desta forma, o criador da propaganda teve sensibilidade matemática ao usar a idéia de proporção para fazer o custo parecer menor, preservando a veracidade da informação. Embora o recurso técnico usado tenha sido uma divisão, é fácil notar que para conceber este texto, mais que o conhecimento da divisão, foi necessário o conhecimento da maneira como as pessoas percebem a noção de proporcionalidade. Assim, o publicitário usou uma técnica matemática simples (a divisão) para potencializar um efeito grande sob o ponto de vista da Matemática cultural.

Nas aulas de Matemática, o uso adequado da divisão em (xii) pode ser comparado com a reportagem (ix) sobre o consultor, na qual a multiplicação foi usada de forma inadequada. Pode-se ainda fazer comparações com a notícia sobre a fazenda Barriguda (vi), onde faltou sensibilidade matemática para esclarecer um fato. Em (xii) a matemática cultural foi usada como um recurso para desviar a atenção de um fato que se queria omitir. Assim, sem entrar em questões éticas, pode-se ver que em (vi), o jornalista não usou a cultura matemática e, assim, fez um trabalho pior. Contrariamente, aqui o publicitário usou sua cultura matemática, para trabalhar melhor.

\section{Matemática nas Leis}

O texto (xiii) a seguir, é parte de uma disposição legal, que rege a construção de condomínios residenciais, em uma certa cidade. O texto (xiv) se refere a um artigo publicado na imprensa, a respeito da legislação criminal brasileira sobre crianças e adolescentes.

xiii) “... as vilas e conjuntos de pequeno porte deverão ser dotadas de áreas livres com, no mínimo, $10 \%$ da área do terreno ... As áreas livres deverão permitir a inscrição de círculo com raio mínimo de 2,50m em toda superfície ...".

Pela forma como está redigida, a lei não permite que um condomínio em um terreno de $1.000 \mathrm{~m}^{2}$ tenha um lote quadrado com $10 \mathrm{~m}$ de lado, como área livre. Para ver isto, basta notar que as partes deste lote, distantes menos que 1 metro de um vértice, não podem estar em um círculo com 2,5m de raio, contido no lote. 
Entretanto na prática esta praça seria aceita, como o autor teve oportunidade de constatar.

Como o objetivo da lei é evitar que a área livre seja excessivamente fragmentada ou que contenha partes muito estreitas, é natural que esta praça seja aceita. Assim, constatamos que a lei está mal formulada, o que possibilita interpretações dúbias que podem ser usadas de forma absolutamente imprevisível.

Tal como aconteceu no texto (i), aqui o defeito de formulação decorre do uso incorreto de noções geométricas. Neste caso, o mal uso de noções matemáticas fez com que o legislador formulasse mal a lei. Desta forma, o uso incorreto da Matemática prejudicou o trabalho do legislador e, por isto, o habitante desta cidade ficou prejudicado.

xiv) Em artigo no qual criticava a legislação brasileira, que estabelece a idade de 18 anos como limite mínimo para que um cidadão possa ser julgado por um crime, o articulista escreveu que "O parâmetro atual estabelece que o limite legal entre maior e menoridade é o dia do 18 - aniversário. Se delinqüir um dia antes, o criminoso é inimputável, se resolver faze-lo 24 horas depois, estará sujeito às penas da lei. Por que? Qual é a diferença?".

Neste caso, o jornalista considerou como uma inadequação na lei, o fato de uma pequena variação de tempo, no momento em que uma infração é cometida, possibilitar uma grande variação no rigor da punição ao infrator. Como este tipo de situação é estudada em Matemática pelas funções contínuas, vemos que o jornalista se valeu de um recurso matemático para expor seu ponto de vista. É interessante observar que em nenhum ponto do artigo, foi feita referência à noção de continuidade. Assim, embora sem usar explicitamente a noção de continuidade; talvez até mesmo sem ter conhecimento desta noção, o jornalista a usou de forma conveniente para escrever um artigo. É interessante notar que o leitor, também não precisa ter conhecimento da noção matemática de continuidade para entender o artigo. Entretanto, a continuidade está presente tanto no raciocínio de quem escreve, como no raciocínio de quem lê.

O professor de Matemática pode discutir este assunto com a turma, quando estudar as funções contínuas. Será interessante observar que o articulista considerou a legislação inadequada, porque o rigor da punição não varia "continuamente" com a idade do infrator. Será ainda interessante observar que desta forma ele conseguiu uma argumentação clara e simples, capaz de ser compreendida pelo leitor. Mais uma vez o estudante verá que o jeito matemático de pensar está estreitamente relacionado com as mais diversas situações da vida. Observará ainda que, neste caso, houve uma inversão no caminho percorrido pelo "jeito". Enquanto nos outros casos estudados neste artigo, o "jeito" ia da situação matemática para a situação não matemática, aqui se deu o oposto. O "jeito" foi da situação não matemática para a situação matemática. 


\section{Discussão nas Aulas de Matemática}

Os textos transcritos neste trabalho deixam claro que as atividades ligadas ao jornalismo, à publicidade e às leis, têm necessidade de fazer uso de Matemática, em uma intensidade bem maior do que se possa imaginar. Esta é uma pequena amostra de um fato geral que revela a necessidade de usar Matemática em quase todas as atividades, tanto por quem presta o serviço, como por quem o recebe.

O professor pode aproveitar estes diversos usos, em suas aulas. Ele pode sugerir que seus alunos procurem situações onde a Matemática esteja presente ou onde sua ausência esteja sendo sentida; onde ela esteja sendo bem ou mal usada. Como se viu, esta procura pode ser feita nas mais diversas situações, tais como jornais, textos publicitários ou legais, programas de TV, declarações de personalidades e muitas outras situações que a vida oferece. Uma vez identificado o recurso matemático (ou a falta que ele fez) o assunto deve ser discutido e os aspectos positivos devem ser enfatizados.

Quanto aos aspectos negativos, uma postura interessante é tentar a sua correção. Assim, ao encontrar um texto mal formulado, o professor pode pedir que os alunos o reformulem. Por exemplo, os alunos podem propor uma nova redação para o texto legal em (xiii). Esta proposta fica ainda melhor se eles decidirem encaminhar o texto corrigido à Câmara dos Vereadores, para que esta tome as devidas providências.

A correção acima é uma proposta interessante e desafiadora. Num curso de aperfeiçoamento de professores onde o autor trabalha, foram feitas algumas tentativas e se verificou que a geometria envolvida, não se limita às questões métricas correntes nos programas escolares. Ela se estende por questões topológicas básicas que envolvem a inclusão de conjuntos. Entretanto, estas questões se colocam de forma perfeitamente integrada com a realidade, o que desperta o interesse dos estudantes. Este interesse facilita em muito, os processos de ensino/aprendizagem.

Há algumas páginas atrás foi discutido o erro nos textos (iii) e (iv) sobre a idade para dirigir ciclomotores. A discussão foi feita porque se constatou que "...uma das informações está errada..." . Entretanto, foi observado que era necessário considerar a hipótese de ambas as informações estarem erradas. Assim, naquela situação a expressão "...uma das informações está errada..." significava que no mínimo uma informação estava errada. Isto é a expressão "...uma das informações está errada..." em vez de significar que "havia exatamente uma informação errada", teve seu sentido usual alterado e passou a significar que "havia pelo menos uma informação errada". Esta discussão coloca a questão do quantificador de existência. O professor pode aproveita-la sempre que precisar de um quantificador.

O fato do quantificador de existência alterar o significado da palavra "existe" que, em Matemática, passa a significar "existe no mínimo um", pode ser comparado com outras situações matemáticas e não matemáticas em que ocorre algo similar. Neste sentido, retornando ao texto (x), vemos que a palavra "losango" teve o seu significado matemático alterado, para informar a posição como os azulejos eram assentados. A mesma coisa ocorreu com a palavra "diagonal" no texto (xi) e com a expressão "hora trabalhada", que teve um significado diferente do usual, no texto (ix). 
O professor pode então constatar que os diversos usos de uma palavra podem alterar seu significado. Na Matemática, isto também acontece. Certas palavras ou expressões adquirem um novo significado, o que por vezes causa problemas nos processos de ensino/aprendizagem. Além do verbo "existir" que foi visto acima, este também é o caso de muitas outras palavras. Por exemplo, a palavra "altura", em geral, está estreitamente associada à verticalidade. Em Geometria, no entanto, ela independe da posição.

Assim, o professor usando os textos acima, pode constatar que em diversas situações da vida, as palavras adquirem significados específicos. Esta constatação certamente o ajudará a convencer seus alunos a aceitarem fato similar em Matemática. Por exemplo, o professor pode levar dois azulejos iguais para a sala. Valendo-se do texto $(\mathrm{x})$, pede a dois alunos que encostem os azulejos no quadro negro, sendo um deles, em "losango". A seguir, observa que independente da posição, os dois azulejos têm a mesma área, uma vez que são iguais. Em seguida ele pede que a turma calcule as áreas para constatar este fato. Para calcular a área do azulejo "em losango", os alunos perceberão que o trabalho ficará mais simples se eles medirem a altura, inclinada. Desta maneira, verão na prática que desvincular a altura da verticalidade, pode ter as suas vantagens.

Procedendo desta forma, o professor estará contribuindo para que o aluno integre a Matemática na cultura básica do cidadão que ele é. Assim, ele desenvolverá a sensibilidade matemática e o jeito matemático de pensar que muito o ajudarão nas mais diversas situações da vida.

Abstract. One objective of this paper is to examine some daily life situations to notice the presence, the absence, the good or bad use of mathematical resources in the approach of such situations. Moreover, we will try to identify the technical or cultural mathematical aspects in the situations mentioned. Another objective is to suggest ways to use this study in the teaching/learning mathematical process in several teaching levels. After all, it is our responsibility - for we are the ones who teach this science - to inform the society and, specially, our students and their families about the possibilities of using Mathematics in several situations in life.

\section{Referências}

[1] L. Lieber, "La Educación Matemática del Hombre de la Calle-Ibéria Editores", Barcelona, 1946.

[2] R.J.C. Valladares, As noções matemáticas no cotidiano, em "Encontro de Educação Matemática do Rio de Janeiro", 1997.

[3] R.J.C. Valladares, The surprising use of Mathematicas in certain profissions, em "Proceedings of CIEAEM 51", (to appear).

[4] R.J.C. Valladares, "Mathematics in the cultural and technical formation of the fitizen", (in preparation). 